\title{
EDITORIAL
}

\section{Brazilian Symposium on Oceanography}

This volume of the Brazilian Journal of Oceanography publishes articles presented during the IV Brazilian Symposium on Oceanography held at the Oceanographic Institute of the University of São Paulo, São Paulo, Brazil, 8-12 December 2008. All the articles appearing in this volume have gone through the normal review process as expected for any article published in the Brazilian Journal of Oceanography.

The main theme of the IV Brazilian Symposium on Oceanography was "Environmental changes: scenarios and adaptations" at their different spatial and time scales. The IVSBO was attended by 308 participants, with a total of 90 oral and 206 poster presentations. Invited scientists from various countries proferred nine keynote lectures comprehending several fields in oceanography.

The Brazilian Symposium on Oceanography derived from the Symposium on Oceanography I, II and III organized in 1989, 1991 and 1996, respectively. This symposium gained national recognition and has been transformed into the Brazilian Symposium on Oceanography, maintaining its regularity since 2002, being an important forum for the discussion of different aspects of the oceanographic sciences.

The IVSBO was sponsored by the Oceanographic Institute of the University of São Paulo (IO/USP), FAPESP, CNPq, Pró-reitoria de Cultura e Extensão Universitária/USP, FUNDESPA, CORPLAB, CPEA and HidroMares.

We are grateful to all the people involved in the organization of the symposium, especially the group of students that made sure that everything ran smoothly. We also take this opportunity to thank the referees for their valuable reviews of the submitted manuscripts.

Eduardo Siegle

Alexander Turra 